\title{
Female Genital Mutilation in Infants and Young Girls: Report of Sixty Cases Observed at the General Hospital of Abobo (Abidjan, Cote D'Ivoire, West Africa)
}

\author{
Kouie Plo, ${ }^{1,2}$ Kouadio Asse, ${ }^{1}$ Dohagneron Seï, ${ }^{1}$ and John Yenan ${ }^{1}$ \\ ${ }^{1}$ Department of Pediatrics, General Hospital of Abobo, 14 PB 125 Abidjan 14, Cote D'Ivoire \\ ${ }^{2}$ Department of Pediatrics, University Teaching Hospital of Bouake, 01 BP 1174 Bouake 01, Cote D’Ivoire \\ Correspondence should be addressed to Kouie Plo; plo.kouie@yahoo.fr
}

Received 8 August 2013; Revised 30 December 2013; Accepted 17 January 2014; Published 4 March 2014

Academic Editor: Hans Juergen Laws

Copyright (@) 2014 Kouie Plo et al. This is an open access article distributed under the Creative Commons Attribution License, which permits unrestricted use, distribution, and reproduction in any medium, provided the original work is properly cited.

\begin{abstract}
The practice of female genital mutilations continues to be recurrent in African communities despite the campaigns, fights, and laws to ban it. A survey was carried out in infants and young girls at the General Hospital of Abobo in Cote D'Ivoire. The purpose of the study was to describe the epidemiological aspects and clinical findings related to FGM in young patients. Four hundred nine (409) females aged from 1 to 12 years and their mothers entered the study after their consent. The results were that 60/409 patients (15\%) were cut. The majority of the young females came from Muslim families (97\%); the earlier age at FGM procedure in patients is less than 5 years: 87\%. Amongst 409 mothers, 250 women underwent FGM which had other daughters cut. Women were mainly involved in the FGM and their motivations were virginity, chastity, body cleanliness, and fear of clitoris similar to penis. Only WHO types I and II were met. If there were no incidental events occurred at the time of the procedure, the obstetrical future of these young females would be compromised. With FGM being a harmful practice, health professionals and NGOs must unite their efforts in people education to abandon the procedure.
\end{abstract}

\section{Introduction}

Female genital mutilation or clitoris cutting (FGM) is defined as the partial or total removal of clitoris and labia. Well known since antiquity in Egypt, this practice is widespread in the world but mainly in Africa [1-7]. Many factors related to tradition, sexual behavior in the males, and religious beliefs impact on FGM [8-11]. The clinical observation of three cases: first in female newborn twins aged three weeks and second in an 8-year girl led us to carry out a prospective study on FGM in infants and young girls. We studied the prevalence and etiologic factors in the pediatric ward at the General Hospital of Abobo, a suburb of Abidjan. Our study also aimed to influence the parents of girls and the traditional circumcisers and practitioners to abandon the practice. Not only are there laws prohibiting FGM, but there are later gynecological and obstetrical consequences of FGM.

Our objectives were (1) to identify FGM in infants and young girls seen in our clinic, (2) to describe the sociocultural context of young girls who had undergone FGM, (3) to assess the mothers' FGM status and attitudes regarding the practice, (4) and to determine the clinical issues in terms of immediate or later complications.

\section{Patients and Methods}

The General Hospital of Abobo is the premier public health entity that takes care of many patients of Abobo and others from periurban areas of Abidjan. This includes about $1,500,000$ inhabitants or $20 \%$ of the population of the city of Abidjan. The pediatric ward enrolls 8,000 outpatients and hospitalizes about 2,500 inpatients a year. Eligible for the survey were infants and young girls seen at the hospital for any reason and whose mothers agreed verbally or by written consent to enter the survey and answer the questionnaire items.

From 16 April to 16 December, 2007, during eight months, 409 infants and young girls aged from 1 to 14 years and 
TABLE 1: Main characteristics of patients' parents.

\begin{tabular}{|c|c|c|c|}
\hline Parents' characteristics & & Number $(\%)$ & \\
\hline \multicolumn{4}{|l|}{ Nationality } \\
\hline Cote d'Ivoire & & $35(58.3)$ & \\
\hline Mali & & $18(30.0)$ & \\
\hline Burkina Faso & & $5(8.3)$ & \\
\hline Benin and Niger & & $2(3.4)$ & \\
\hline \multicolumn{4}{|l|}{ Ethnic groups } \\
\hline Malinke and Senoufo (Cote d'Ivoire) & & $35(58.3)$ & \\
\hline Malinke, Bambara, Dogon, and Peulh (Mali) & & $18(30.0)$ & \\
\hline Senoufo (Burkina Faso) & & $5(8.3)$ & \\
\hline Hausas (Benin and Niger) & & $2(3.4)$ & \\
\hline \multicolumn{4}{|l|}{ Religion } \\
\hline Muslim & & $59(98.3)$ & \\
\hline Christian & & $1(1.7)$ & \\
\hline Level of education & Mothers & & Fathers \\
\hline Analphabets & $40(66.7)$ & & $33(55.0)$ \\
\hline Primary school & $9(15.0)$ & & $19(31.7)$ \\
\hline Secondary school & $6(10.0)$ & & $5(8.3)$ \\
\hline High school & $5(8.3)$ & & $3(5.0)$ \\
\hline \multicolumn{4}{|l|}{ Decision makers } \\
\hline Grandmothers & & $43(71.6)$ & \\
\hline Mothers and aunts & & $15(25.0)$ & \\
\hline Fathers & & $2(3.4)$ & \\
\hline \multicolumn{4}{|l|}{ Parents' motivations } \\
\hline Virginity and chastity & & $60(100.0)$ & \\
\hline Body cleanliness & & $38(63.3)$ & \\
\hline Clitoris: male organ and harmful & & $38(63.3)$ & \\
\hline
\end{tabular}

their mothers entered the prospective study. The FGM status of girls was recorded during in- or outpatient visits. These examinations were complemented by a questionnaire comprising four groups of items: (1) patient's identification with age, native region (north, south, east, west, and center of the country), ethnic group, religion, and nationality; (2) history and circumstances of FGM practice, age at FGM procedure, observance of ritual ceremony or not, the individuals behind the decision of FGM practice, and the motivations; the circumciser (childbirth attendant or matron), tools used for FGM, and the occurrence of immediate complications such as bleeding, the medicines used to heal the wounds, the rituals observed during the FGM ceremony, time elapsing before full wound healing, and the FGM status of the mothers themselves; (3) evidence of FGM by a physical general examination including the genitalia and classification of FGM, when present, according to the World Health Organization's (WHO) classification [12]: these are type I: Sunna partial or total removal of the clitoris and/or the prepuce or excision, type II: partial or total removal of the clitoris and the labia minora, with or without excision of the labia majora (clitoredectomy), type III: narrowing of the vaginal orifice with creation of a covering seal by cutting and apposing the labia minora and/or the labia majora with or without excision of the clitoris (infibulations or pharaonic circumcision), and type IV: all other harmful procedures to the female genitalia for nonmedical purposes piercing, pricking, incising, scraping, and cauterization of the genitalia area (unclassifiable).

Ethics of Our Study. The General Hospital Consultative Committee that evaluates the relevance, feasibility, confidentiality of the information obtained, and ethnical aspects of clinical research reviewed our protocol of research and gave its permission. Once the mother's oral or written consent was obtained, the same female physician organized the questionnaire, performed the physical examinations, and filled out the data sheets during both inpatients and outpatients consultations.

\section{Results}

Sixty of 409 infants and young girls (15\%) were diagnosed as having undergone FGM. Their age distribution at the time of consultation or hospitalization was between 1 and 5 years: 19, (32\%) between 5 and 10 years: 29 (48\%) and between 10 and 15 years: 12 (20\%). The baseline characteristics on epidemiological aspects were the earlier age at FGM practice, 19 infants under one-year old; women were the individuals behind the decision of FGM practice (96.60\%); several West 
TABLE 2: Characteristics of infants and young girls undergone FGM.

\begin{tabular}{|c|c|}
\hline Patients' characteristics & Number (\%) \\
\hline \multicolumn{2}{|c|}{ Age at FGM practice (years) ${ }^{1}$} \\
\hline$<1$ & $19(31.7)$ \\
\hline$(1-5)$ & $29(48.3)$ \\
\hline$(5-10)$ & $12(20.0)$ \\
\hline \multicolumn{2}{|c|}{ FGM classification (WHO) } \\
\hline Type I & $8(13.3)$ \\
\hline Type II & $52(86.7)$ \\
\hline \multicolumn{2}{|c|}{ Symptoms reported after FGM ${ }^{2}$} \\
\hline Pain & $60(100.0)$ \\
\hline Fever & $47(78.3)$ \\
\hline Minimal bleeding & $60(100.0)$ \\
\hline \multicolumn{2}{|c|}{$\begin{array}{l}{ }^{1} \text { Areas where FGM took place: Abobo and Adjamé ( } 35 \text { or } 58 \% \text { in Abidjan); } \\
\text { Korhogo, Ferkessedougou, Odienne, and Boundiali: } 11 \text { (Northern region of } \\
\text { Cote d'Ivoire); Kaye, Mopti, Boroni, and Bonangoro } 14 \text { (23\%) in Mali. All the } \\
\text { FGMs were performed in circumcisers' home with knives, razors, or blades. } \\
{ }^{2} \text { Each girl could have one or more symptoms. }\end{array}$} \\
\hline
\end{tabular}

TABLE 3: Distribution of patients according to the age at FGM practice and FGM types.

\begin{tabular}{lccc}
\hline \multirow{2}{*}{ Age at FGM practice (years) } & \multicolumn{4}{c}{ FGM classification (WHO) } \\
& Type I & Type II & Total \\
\hline$<1$ & 0 & 19 & 19 \\
$1-5$ & 1 & 28 & 29 \\
$5-10$ & 7 & 5 & 12 \\
\hline Total & 8 & 52 & 60 \\
\hline
\end{tabular}

There is a high risk to have undergone FGM type II between 1-5 years (IC 95\% $P$ value $<0.05)$.

African ethnic groups from Cote d'Ivoire, Mali, Burkina Faso, Benin, and Niger were implicated; Muslim families 59/60 and the illiterate or low educational level of the parents $81 \%$ and $87 \%$, respectively in mothers and fathers were found as major factors. The practitioners were traditional circumcisers; no nurses, midwives, or physicians were involved.

About the clinical findings, only FGM types I and II were diagnosed. Pain, fever, and minimal bleeding were the main symptoms and signs disclosed by the mothers surveyed. There was a potential relative risk of undergoing type II mutilation for those under five years of age. Amongst the mothers, 250 women out of 409 had had FGM (61.1\%). Among them, 151 had their daughters (60.4\%) undergone the procedure. The details of sociocultural characteristics of our samples and the clinical findings of our patients are reported on the Tables 1, 2, and 3 and Figure 1 shows a FGM type II in a 1-year-old Peulh female.

\section{Discussion}

4.1. Epidemiology. The prevalence of FGM among our patients population was $15 \%$. The main associated factors were as follows: women were the decision makers relative to FGM; in $97 \%$ of cases, it was a grandmother, mother, or aunt who

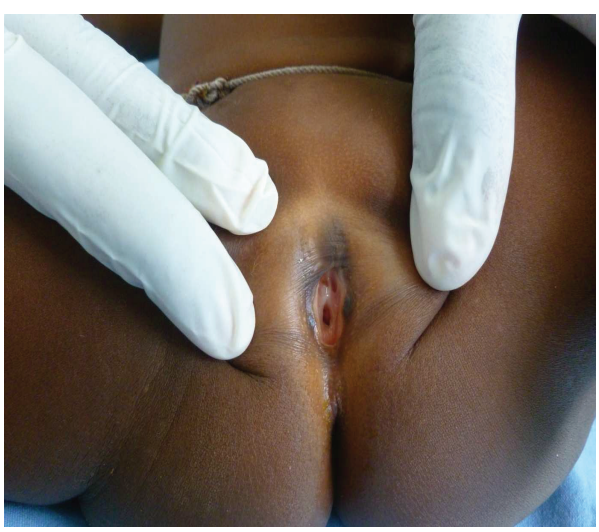

Figure 1: FCM type II in a 1-year-old Peulh female (picture photographed in our ward of pediatrics).

initiated the operation. Their chief motivations encompassed chastity (100\%) and esthetics (68\%).

FGM was encountered most often in the communities of three countries with a relative high rate in some ethnic groups as the Malinke and Senoufo. Most families were Muslim (98.3\%) and most parents were illiterate, $81 \%$ and $87 \%$ in mothers and fathers, respectively.

Previous reports on FGM in West African women [13-17] gave rates varying from 45 to $60 \%$ in the general population and 20 up to $87 \%$ in northern and western regions of the country. Rates were high among the Dan, Malinke, Wè, and Senoufo ethnic groups. The proportion of young girls has been estimated by Oulaï in his report to be about 500 females. Those were $31 \%$ for 155 children between 0 and 5 years; $31.4 \%$ for 157 between 12 and 16 years of age; and 38.6\% in 193 women.

The majority were of the Dan group (80.12\%); $94.6 \%$ were illiterate. Only $5.4 \%$ had had a primary and secondary school level of education. The religions were distributed in this way: Christians: $55.91 \%$, Muslims: $43.34 \%$, and animists $0.75 \%$ [18]. The decision makers were mainly women: grandmothers $(71.6 \%)$, mothers $(25.0 \%)$, and fathers $(3.4 \%)$. In a survey carried out in 38,816 Egyptian young school girls the prevalence of FGM was $50.3 \%(19,543)$. The motivations were religion: $33.4 \%$, cleanliness for girls: $18.9 \%$, cultural and ancient tradition: $17.9 \%$, and chastity $15 \%$. Compared to the study of Snow et al. in Nigeria, similar characteristics had been found amongst young girls and women between 15 and 49 years victims of FGM and interviewed: age at FGM prior one year 371 (68.3\%), between one and ten years $43(7.9 \%)$, and ten to twenty years $88(16.3 \%)$ [19]. The religious context in this study was Pentecostals: 562 (33.1\%), Protestants 277 (16.3\%), Catholics 613 (36.1\%), Muslim 100 (5.9\%), and others 146 (8.6\%). On the other hand educational level of the surveyed girls was distributed as follows: primary: 330 (19.3\%), secondary: 533 (32.2\%), tertiary 767 (44.9\%), and none 77 (4.5\%) showing the inhomogeneous and spatial distribution of sociocultural factors in the practice of FGM. The commonest basis would be the ancient and tradition beliefs $[20,21]$. These observations are similar to those in data from Burkina Faso, Mali, Guinea, and Gambia in West Africa [22]. 
4.2. Clinical Findings and FGM Classification. About the clinical findings, FGM types I and II accounted for 100\% of cases whereas in Somalia, Sudan and Egypt, Mali, and Burkina Faso types III and IV were mentioned up to 89\% [2325]. The immediate complications, such as pain, fever, and minimal or incidental bleeding as short period of bleeding (if it is severe) could be catastrophic, were probably underestimated. Hemorrhages, infections, and death have been reported together with the posttraumatic stress disorders and memory problems $[26,27]$. What is the future of our patients? Most did not have major long-term complications, after the fear and the psychological trauma of FGM, finding similar to those of Althaus [28].

These infants and young girls, once adults, could nonetheless face the late consequences of FGM. These include psychological, gynecological, and obstetrical difficulties. Painful intercourse, bleeding, dystocia, long labor, and episiotomy needed at the time of labor have been reported by gynecologists and many nongovernmental organizations fighting for the abandonment of FGM $[29,30]$.

Although in our study no major psychological troubles were encountered, posttraumatic stress disorders have been reported in patients similar to ours [31-35].

4.3. Elimination of FGM. Many African countries and elsewhere in the world have laws prohibiting FGM. Nongovernmental organizations (NGOs) campaigns against FGM continue to fight for its abandonment [36-40]. Despite these laws and campaigns to eliminate it, FGM continues in urban and rural areas, as our study and other recent reports have shown $[41,42]$.

\section{Conclusion}

Our study has shown the current reality of FGM in earlier age. It resulted from traditional and religious beliefs. Women, having a past history of FGM, play the key role in the occurrence of FGM in their daughters. Only types I and II mutilations have been met.

There were few immediate complications. The combination of law-enforcement together with information and education activities by NGO's aimed at female populations has curtailed FGM in most countries. Continuing efforts are needed to eliminate FGM as a threat to the health and wellbeing of women.

\section{Conflict of Interests}

On behalf of all the authors of this paper Kouie Plo states and certifies that there is no conflict of interests in the publication of this report. The authors did not receive any finance for this survey.

\section{Acknowledgments}

The authors would like to thank the Head of the General Hospital of Abobo and the members of the Consultative Committee for its approval, Professor Emeritus Giulio John
D'Angio, formerly at the Department of Radiation Oncology at the University of Pennsylvania, Philadelphia, PA, USA, for the prereview and improvement of the final manuscript.

\section{References}

[1] E. Herieka and J. Dhar, "Female genital mutilation in the Sudan: survey of the attitude of Khartoum University students towards this practice," Sexually Transmitted Infections, vol. 79, no. 3, pp. 220-223, 2003.

[2] L. Morison, C. Scherf, G. Ekpo et al., "The long-term reproductive health consequences of female genital cutting in rural Gambia: a community-based survey," Tropical Medicine and International Health, vol. 6, no. 8, pp. 643-653, 2001.

[3] M. A. Tag-Eldin, M. A. Gadallah, M. N. Al-Tayeb, M. AbdelAty, E. Mansour, and M. Sallem, "Prevalence of female genital cutting among Egyptian girls," Bulletin of the World Health Organization, vol. 86, no. 4, pp. 269-274, 2008.

[4] P. S. Yoder and M. Mahy, Female Genital Cutting in Guinea: Qualitative and Quantitative Research Strategies, vol. 5 of DHS Analytical Studies, DHS, Calverton, Md, USA, 2001.

[5] P. S. Yoder and S. Khan, "Numbers of women circumcised in Africa: the production of a total," Demographic Health Research, DHS Working Papers no. 39, Macro, 2008.

[6] G. A. O. Magoha and O. B. Magoha, "Current global status of female genital mutilation: a review," East African Medical Journal, vol. 77, no. 5, pp. 268-272, 2000.

[7] D. Dubourg, F. Richard, R. Eggermont et al., "Etudes des femmes excisées et des filles à risque d'excision en Belgique," Institut de Médecine Tropicale, 2010.

[8] S. Faizang, "Circoncision, excision et rapports de domination," Anthropologie Et Société, vol. 9, no. 1, pp. 117-127, 1985.

[9] R. A. Shweder, "What about female genital mutilation? And why understanding culture matters the first place," in Engaging Cultural Differences: The Multicultural Challenge in Liberal Democracies, R. Shweder, M. Minow, and H. Markus, Eds., pp. 216-225, Russell Sage Foundation, New York, NY, USA, 2002.

[10] C. Ibe and C. Johnson-Agbakwu, "Female genital cutting: addressing the issues of culture and ethics," The Female Patient, vol. 36, pp. 28-31, 2011.

[11] J. Whitehorn, O. Ayonrinde, and S. Maingay, "Female genital mutilation: cultural and psychological implications," Sexual and Relationship Therapy, vol. 17, no. 2, pp. 161-170, 2002.

[12] World Health Organization, "Female genital mutilation," Report of a WHO Technical Working Group, World Health Organization, Geneva, Switzerland, 1995.

[13] UNICEF, "History and estimated prevalence among women aged 15-49 years," MICS, 2006, http://www.orchildproject.org/ category/resources/country-pages/page3.

[14] MICS, WHO, DHS, and UNICEF Côte d'Ivoire, "Overview of female genital mutilation/cutting," Unicef DHS 1994, 1998/ 1999, http://www.childinfo.org/files/CotedIvoire_FGC_profile_ English.pdf.

[15] J. C. Oulai, La pratique de l'excision dans la région de Logoualé (Côte-d'Ivoire) [Ph.D. thesis], Université d'Abidjan, 2006.

[16] UNICEF, Benin DSH, "Overview of female genital mutilation/cutting. FGM/country profile," 2001, http://www.childinfo .org/files/Benin_FGC_profile_English.pdf.

[17] UNICEF, Niger DSH, "Overview of female genital mutilation/cutting," 1998, http://www.childinfo.org/files/Niger_FGC_ profile_English.pdf. 
[18] N. J. Diop, Z. Congo, A. Ouédraogo et al., "Analysis of the evolution of the practice of female genital mutilation/cutting in Burkina Faso," Population Council Frontiers Reproductive Health, USAID, 2008.

[19] R. C. Snow, T. E. Slanger, F. E. Okonofua, F. Oronsaye, and J. Wacker, "Female genital cutting in southern urban and periurban Nigeria: delf-reported validity, social determinants and secular decline," Tropical Medicine and International Health, vol. 7, no. 1, pp. 91-100, 2002.

[20] C. Feldman-Jacobs and D. Clifton, "Female genital mutilation/cutting: data and trends," Population Reference Bureau, USAID, 2010.

[21] P. S. Yoder, N. Abderrahim, and A. Zhuzhuni, "Female genital cutting in the demographic and health surveys: a critical and comparative analysis," DHS Comparative Reports no. 7, ORC Macro, Calverton, Md, USA, 2004.

[22] P. S. Yoder and S. Khan, "Numbers of women circumcised in Africa: the production of a total," Demographic Health Research, DHS Working Papers no. 39, Macro, 2008.

[23] D. M. Westley, "Female circumcision and infibulation in Africa," Electronic Journal of Africana Bibliography, vol. 4, pp. 1-50, 1999.

[24] L. Almroth, Genital Mutilation of Girls in Sudan: Community and Hospital-Based Studies on Female Genital Cutting and Its Sequelae, Karolinska University Press, Stockholm, Sweden, 2005.

[25] H. Jones, N. Diop, I. Askew, and I. Kaboré, "Female genital cutting practices in Burkina Faso and Mali and their negative health outcomes," Studies in Family Planning, vol. 30, no. 3, pp. 219-230, 1999.

[26] D. O. Osifo and I. Evbuomwan, "Female genital mutilation among Edo people: the complications and pattern of presentation at a pediatric surgery unit, Benin City," African Journal of Reproductive Health, vol. 13, no. 1, pp. 17-25, 2009.

[27] A. R. Oduro, P. Ansah, A. Hodgson et al., "Trends in the prevalence of female genital mutilation and its effect on delivery outcomes in Kassena-Nankana district of Northern Ghana," Ghana Medical Journal, vol. 40, no. 3, pp. 87-92, 2006.

[28] F. A. Althaus, "Female circumcision: rite of passage or violation of rights?” International Family Planning Perspectives, vol. 23, no. 3, pp. 130-133, 1997.

[29] M. Brady, "Female genital mutilation: complications and risk of HIV transmission," AIDS Patient Care and STDs, vol. 13, no. 12, pp. 709-716, 1999.

[30] A. Behrendt and S. Moritz, "Posttraumatic stress disorder and memory problems after female genital mutilation," The American Journal of Psychiatry, vol. 162, no. 5, pp. 1000-1002, 2005.

[31] J. I. Kizilhan, "Impact of psychological disorders after female genital mutilation among Kurdish girls in Northern Iraq," European Journal of Psychiatry, vol. 25, no. 2, pp. 92-100, 2011.

[32] American Academy of Pediatrics Committee on Bioethics, "Ritual genital cutting of female minors," Pediatrics, vol. 125, no. 5, pp. 1088-1093, 2010.

[33] D. M. Elsayed, R. M. Elamin, and S. M. Sulaiman, "Female genital mutilation and ethical issue," Sudanese Journal of Public Health, vol. 6, no. 2, pp. 63-67, 2011.

[34] UNICEF, "The impact of a harmful traditional practice on child girl," Ras-Work B UNICEF, Innocenti Research Centre, Florence, Italy, 2006.

[35] A. Rahman and N. Toubia, Female Genital Mutilation: A Guide to Laws and Policies Worldwide, Center for Reproductive Law \& Policy Rainbo, Zed, London, UK, 2000.
[36] E. Finke, "Genital mutilation as an expression of power structures: ending FGM through education, empowerment of women and removal of taboos," African Journal of Reproductive Health, vol. 10, no. 2, pp. 13-17, 2006.

[37] OHCHR, UNAIDS, UNDP et al., "Eliminating female genital mutilation: an interagency statement," 2008.

[38] I. Askew, "Methodological issues in measuring the impact of interventions against female genital cutting," Culture, Health \& Sexuality, vol. 7, no. 5, pp. 463-477, 2005.

[39] W. Zuckerman, "Female genital mutilation becomes less common in Egypt," New Scientist, vol. 17, article 22, 2011.

[40] E. Denison, R. C. Berg, S. Lewin et al., "Effectiveness of interventions designed to reduce the prevalence of female genital mutilation/cutting," Systematic Report no. 25, Kunnskapssenteret Norwegian Knowledge Center for the Health Sciences, Oslo, Norway, 2005.

[41] E. Dorkenoo and S. Elworthy, "Female genital mutilation: proposals for change," Health and Medicine, Minority Rights, London, UK, 1992.

[42] UNICEF Innocenti Research Centre, "Changing a harmful social convention: female genital mutilation/cutting," Innocenti Digest, Florence, Italy, 2005. 


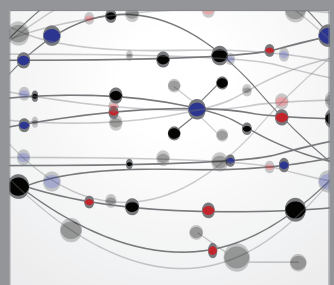

The Scientific World Journal
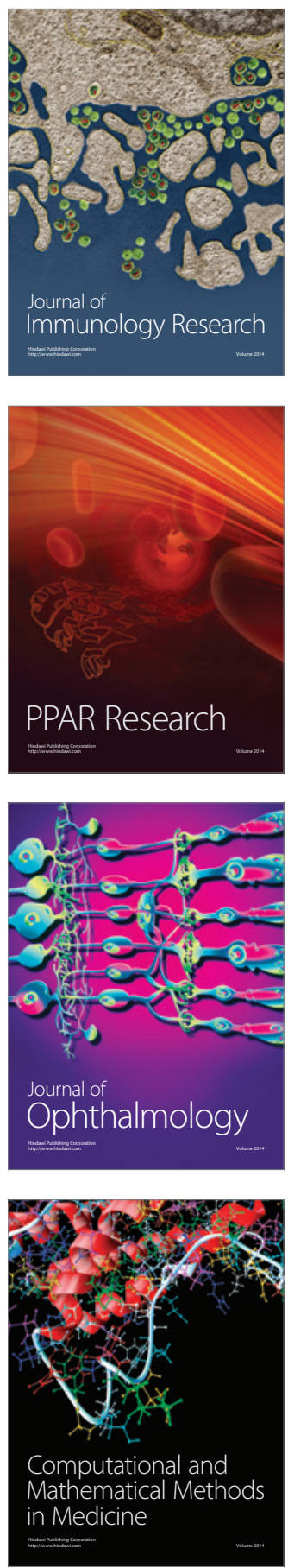

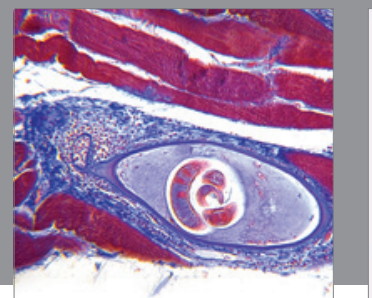

Gastroenterology

Research and Practice
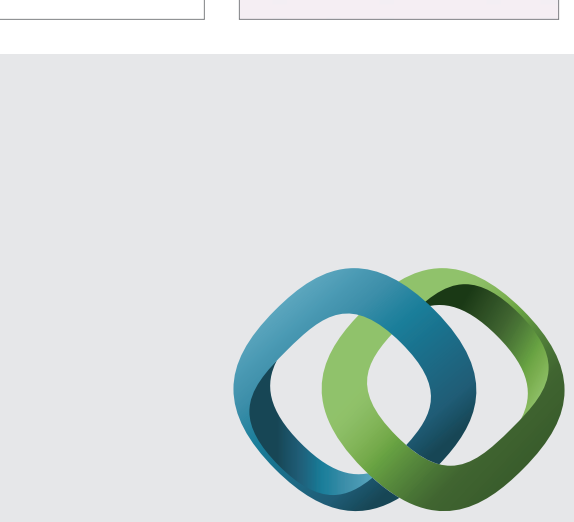

\section{Hindawi}

Submit your manuscripts at

http://www.hindawi.com
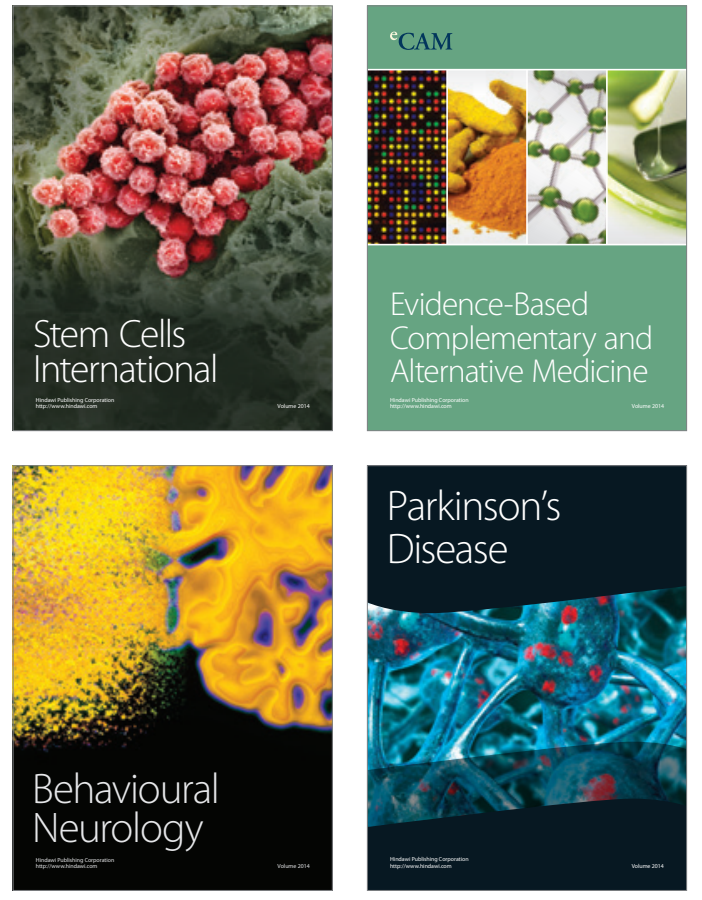
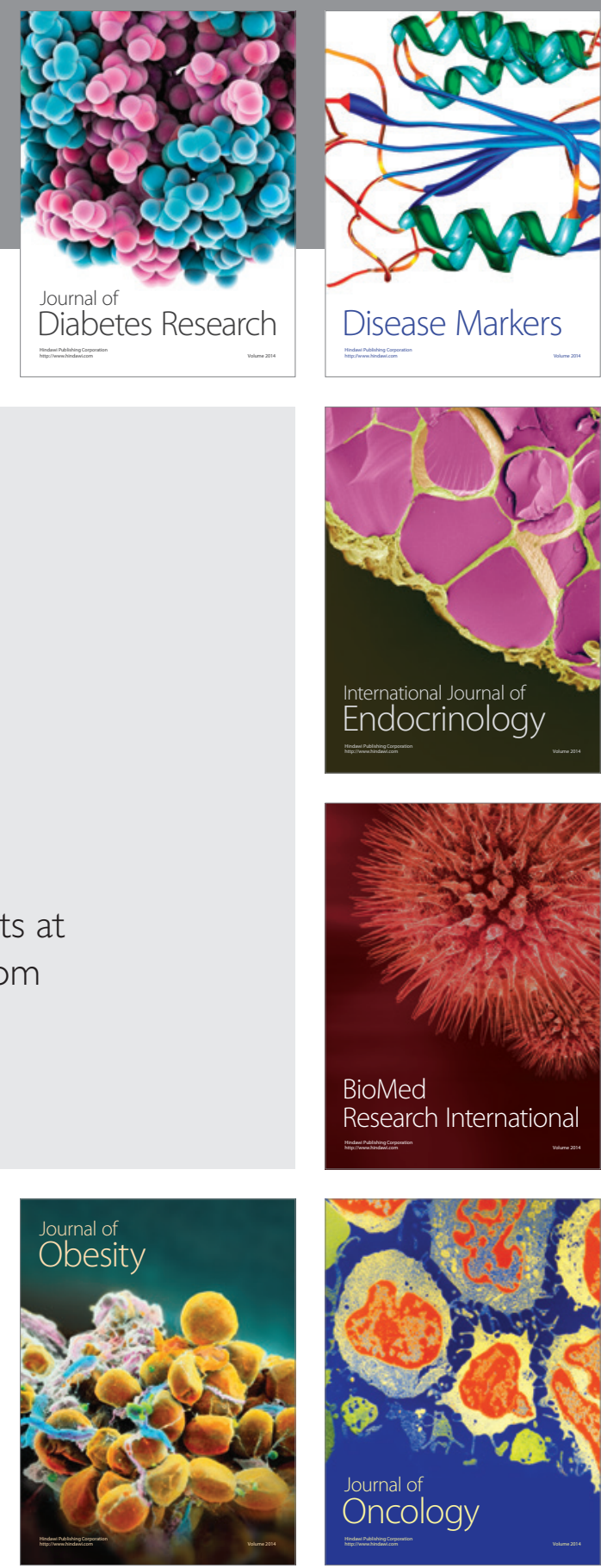

Disease Markers
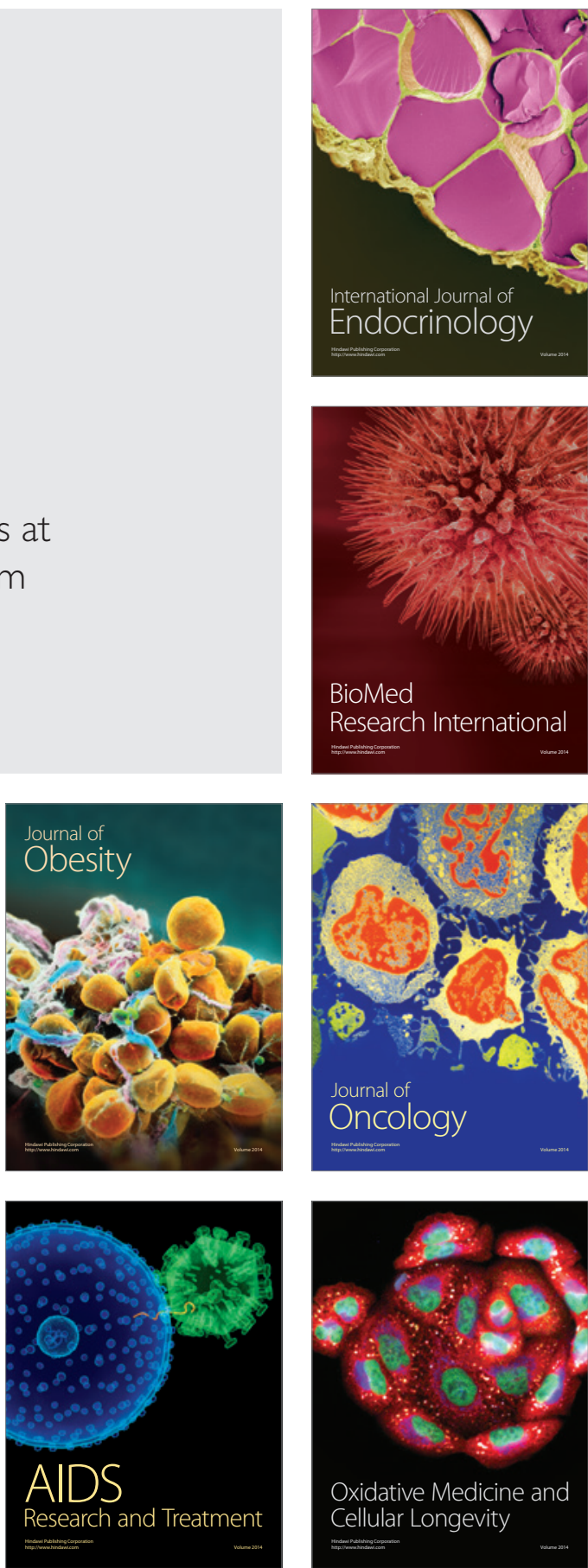